\title{
Differential Responses of Colletotrichum gloeosporioides and C. truncatum Isolates from Different Hosts to Multiple Fungicides Based on Two Assays
}

\author{
Sephra N. Rampersad and Lisa D. Teelucksingh, The University of the West Indies, Department of Life Sciences, Faculty of Science \\ and Agriculture, St. Augustine, Trinidad and Tobago, West Indies
}

\begin{abstract}
Rampersad, S. N., and Teelucksingh, L. D. 2012. Differential responses of Colletotrichum gloeosporioides and C. truncatum isolates from different hosts to multiple fungicides based on two assays. Plant Dis. 96:1526-1536.

Anthracnose is one of the most important postharvest diseases of many economically important crops worldwide. This study was conducted with the objective of investigating the sensitivity of Colletotrichum gloeosporioides and C. truncatum isolates to multiple fungicides with different modes of action. The study analyzed quantitative sensitivity data derived from conventional amended agar (AA) assays and qualitative spore responses obtained from a novel microtiter bioassay that is based on reduction of a viability dye, Alamar blue (AB). Generally, for AA assays, the percent growth inhibition (\%RGI) increased with increasing concentration for all isolates and all fungicides, except for copper hydroxide. C. truncatum isolates reacted differently to increasing concentrations of the various fungicides depending on whether the isolates originated from pepper or papaya. C. truncatum from pepper had generally less \% RGI than $C$. truncatum isolates from papaya. $C$. gloeosporioides isolates from papaya had generally higher \%RGI than C. truncatum isolates for all concentrations tested for pyraclostrobin, chlorothalonil, and fosetyl-aluminum. C. gloeosporioides isolates from pepper had generally higher \%RGI than $C$. truncatum isolates for all

concentrations tested for most fungicides. In all cases, Colletotrichum sp. and fungicide had significant $(P \leq 0.001)$ effects on the $\log$ concentration of fungicide for which relative growth was inhibited by 50 and 90\% (log EC50 and $\log$ EC90, respectively) calculated for all isolates, regardless of whether values were compared for only $C$. gloeosporioides isolates or only $C$. truncatum isolates. Correlation analyses of $\log$ EC50 and $\log$ EC90 values of all the isolates revealed a nonsignificant association for pyraclostrobin. In $\mathrm{AB}$ assays, all fungicides had an equivalent effect at inhibiting spore germination at the lower concentrations. According to binary logistic regression analyses, species, isolate, and fungicide concentration had significant predictive value in determining whether an $\mathrm{AB}$ test would be positive. Sequence alignments between $C$. gloeosporioides isolates and $C$. gloeosporioides f. sp. aeschynomene revealed no base substitutions at codons 198, 199, 200, and 240; however, sequence comparisons between $C$. truncatum isolates and $C$. gloeosporioides $\mathrm{f}$. sp. aeschynomene revealed two codon changes located outside of the identified codon 198 or 200 associated with the benzimidazole-resistant phenotype of $C$. gloeosporioides isolates.
\end{abstract}

Filamentous fungi that are members of the genus Colletotrichum are one of the most destructive plant pathogens worldwide (10). These fungi are responsible for anthracnose disease, which is one of the most economically important postharvest diseases of a wide range of tropical and subtropical fruit $(33,47,53)$. Infection results in severe losses due to significant reductions in fruit quantity, quality, and product value. Effective control of Colletotrichum infection usually involves the use of a combination of cultural, biological, and chemical control and intrinsic resistance. The pathogen's ability to cause quiescent or latent infections at both the pre- and postharvest stages; spore dispersal by surface water or rain splash; continuous cropping practices supported by tropical climates, which ensure rapid build-up of inoculum; a lack of commercially available resistant cultivars, especially for fruit crops; and development of resistance to certain fungicides challenge successful management of Colletotrichum infection $(23,29,34)$.

Fungicides are used extensively for post-harvest disease control in fruit and vegetables caused by Colletotrichum spp.; however, their use may be restricted by the relative efficacy of the fungicide, the Colletotrichum sp. associated with infection, the time of infection, the availability of the product for a specific host species, inoculum density and disease pressure, negative effects on fruit ripen-

Corresponding author: S. N. Rampersad,

E-mail: sephra.rampersad@sta.uwi.edu

* The $\boldsymbol{e}$-Xtra logo stands for "electronic extra" and indicates that Figures 1 and 2 appear in color online.

Accepted for publication 8 May 2012.

http://dx.doi.org/10.1094/PDIS-10-11-0906-RE

(C) 2012 The American Phytopathological Society ing, phytotoxic effects, prevailing climatic conditions, and pesticide regulations that apply to producing countries as well as destination countries with specific importation restrictions (47).

Avocado (Persea americana Mill.), mango (Mangifera indica L.), and papaya (Carica papaya L.) are among the top 10 tropical fruit crops that are produced worldwide (27). In Trinidad, avocado, mango, and papaya production increased between 30 and $40 \%$ over the last 10 years to accommodate export and various processing markets (27). Anthracnose disease of these fruit is arguably one of the most economically important diseases throughout production areas and is usually caused by Colletotrichum gloeosporioides although $C$. acutatum has also been implicated in some locations $(21,24,61,68)$. In addition to C. gloeosporioides, C. truncatum (synonym $C$. capsici; 19 ) has also been reported to infect papaya in Trinidad (57), Indonesia (60), Florida (64), Mexico (63), and Japan (70).

Generally, chemical control of anthracnose in these fruit crops includes the use of dithiocarbamates such as zineb, maneb, and captan but mancozeb use is restricted in fruit carded for export to certain countries due to residue accumulation on fruit surfaces $(2,8)$. Copper fungicides and benomyl, when applied as pretreatments, delayed onset of symptoms in mango, avocado, and papaya $(4,5,59)$. In Trinidad, alternating applications of mancozeb, benomyl, copper fungicides, and, more recently in some fields in South Trinidad, pyraclostrobin are used to control a number of fungal diseases in papaya, including anthracnose and Phytophthora fruit rot. Little to no chemical control is used for anthracnose of mango and avocado in Trinidad.

C. gloeosporioides and C. acutatum are commonly associated with anthracnose of pepper; however, in Trinidad, the disease on red-ripe fruit is caused by both $C$. gloeosporioides and $C$. truncatum (Ramdial and S. N. Rampersad, unpublished data). To date, there are no reports of the disease on immature green fruit (40). Chemical control of bell pepper anthracnose include the use of 
copper fungicides, chlorothalonil (alone or in mixes), maneb, and, more recently, strobilurins such as azoxystrobin, trifloxystrobin, and pyraclostrobin (alone or in mixes; 40,62). In Trinidad, chlorothalonil, benomyl, and copper fungicides are used to control fungal pathogens in bell pepper. Thiophanate-methyl and tolclofos-methyl are generally used in soil preparation prior to planting.

Conventional methods to assess fungicide sensitivity are based on measuring radial diameter of colonies on amended agar (AA) compared with growth on nonamended agar $(6,7)$; however, these methods only monitor mycelial growth and cannot determine the effects of chemicals on spore viability. The Alamar blue $(\mathrm{AB})$ assay monitors the reducing environment that is indicative of metabolically active cells or spores. The reducing environment of the cells or spores is measured through the conversion of resazurin (oxidized form of the dye is blue) to resorufin (reduced form of the dye is pink) either colorimetrically or fluorimetrically. The assay, therefore, can be performed with the objective of attaining qualitative (visual inspection for color change of the dye) or quantitative (absorbance or fluorescence) measurements of cell or spore viability. Compared with other viability dyes, AB dye is (i) water soluble; (ii) nontoxic to cells, resulting in no metabolic interference; (iii) nontoxic to user because it is noncarcinogenic; (iv) stable in culture, which allows continuous monitoring of cells over a period of time; and (v) nontoxic to the environment, so that there are no organic waste disposal issues $(1,54,65)$. One disadvantage of this assay, however, is that it is not a direct cell-counting technique like hemocytometry, and the absorbance or fluorescence signal can be affected by a number of factors, including cell or spore density, incubation time and temperature, $\mathrm{pH}$ and nutrient content of the medium, and addition of chemicals that reduce the dye $(1,54,57)$. Initially, $A B$ has been used over the past 50 years in studies pertaining to cell viability and cytotoxicity in a range of biological and environmental systems, including the assessment of antimicrobial compounds $(3,17,28,39,43,44,51,52)$. It offers several advantages over other metabolic indicators and other methods of measuring cell viability and cell proliferation. However, as with any bioassay, suitability must be determined for each application and cell model. Recently, the assay has been applied to studying fungicide sensitivity of plant pathogens Monilinia fructicola (18), Botrytis cinerea (49), Verticillium dahliae (56), and Alternaria alternata (66). By investigating fungicide sensitivity using both conventional AA and spore-viability assays, a more complete assessment of the impact of various fungicides with different modes of action on survival of the fungus can be obtained because two fitness parameters, mycelial growth and spore viability, can be evaluated.

To effectively manage anthracnose disease in a number of economically important plant species, it is critical to determine the relative fungicide sensitivity of the Colletotrichum spp. responsible for these infections. In Trinidad, it is uncertain whether Colletotrichum isolates have developed resistance to commonly used fungicides to control anthracnose disease of avocado, mango, papaya, and bell pepper or whether a lack of effective control is due to use of fungicides that have little effect on a given Colletotrichum sp. responsible for disease. The objectives of this study were to (i) evaluate the relative fungicide sensitivities of $C$. gloeosporioides and $C$. truncatum isolates from various host species (avocado, mango, papaya, and bell pepper) to fungicides with different modes of action based on two methods of chemical toxicity testing, (ii) determine the percent relative growth inhibition and $\log \mathrm{EC}$ values for these isolates based on AA tests, (iii) assess the effects of increasing concentration of fungicides on spore respiration based on qualitative $\mathrm{AB}$ tests, (iii) evaluate the effects of Colletotrichum spp. on fungicide sensitivity, and (iv) characterize benomyl-resistant genotypes based on amino acid sequence comparisons of the $\beta$-tubulin gene.

\section{Materials and Methods}

Collection of isolates. Isolates were collected during the period August 2009 to June 2010 from avocado, mango, papaya, and bell pepper cultivations throughout Trinidad. Isolations were made by first surface sterilizing the infected material (rinsing in $0.6 \%$ sodium hypochlorite for $1 \mathrm{~min}$, rinsing in $70 \%$ ethanol for $2 \mathrm{~min}$, then a final washing in sterile distilled water for $2 \mathrm{~min}$ ). A $4-\mathrm{mm}^{3}$ section of tissue taken from the edge of the lesion was plated on $2 \%$ water agar (BactoAgar; Difco Laboratories) supplemented with streptomycin, tetracycline, and chloramphenicol (Sigma-Aldrich) at $50 \mathrm{mg} /$ liter each. Cultures were incubated at $25 \pm 1{ }^{\circ} \mathrm{C}$ for 5 days. Emerging colonies were then transferred to potato dextrose agar (PDA; Oxoid Ltd.). Monoconidial cultures were then prepared and used in subsequent assays. Avocado and mango isolates were considered to give baseline responses for all of the fungicides tested in this study because none of these fungicides were used in the orchards from which these isolates were collected. Conversely, papaya and pepper isolates were collected from fields with a 5-year spray history of Acrobat, Banrot, benomyl, Mankocide, Rizolex, Vacomil, and copper-based fungicides. Bellis, Cabrio, and Polyram were relatively new fungicides on the market and there was only one report of Bellis use that started in 2010 in papaya cultivations in South Trinidad. Importantly, it should be noted that growers generally apply a cocktail of pesticides, and the mix ratio and application rates may or may not follow the recommended guidelines of the manufacturer.

Molecular characterization of isolates. Total genomic DNA was isolated using the E.Z.N.A. SP fungal DNA extraction kit (Omega Bio-tek Inc.). Polymerase chain reaction (PCR) amplification was carried out using internal transcribed spacer (ITS) 4 and -5 primers that target the internally transcribed spacer region of the nuclear ITS1-5.8S-ITS2 rDNA (67) and $\mathrm{Bt} 2 \mathrm{a} / \mathrm{b}$ primers that partially amplify the $\beta$-tubulin gene (31). PCR products were sequenced in both directions (Amplicon Express). Comparisons were made with sequences available on the GenBank database using the gapped BLAST algorithm in order to confirm the identity of the isolates. To determine whether sensitivity to benomyl was due to base substitutions in the $\beta$-tubulin region, TUB2-L/R primers were utilized (51). PCR products were sequenced and the translated nucleotide sequences were compared with cognate sequences of the $\beta$-tubulin gene of reference type $C$. gloeosporioides f. sp. aeschynomene (GenBank accession number U14138) (14). Amino acid sequence alignments and identification of codon changes were carried out using the MegAlign module of Lasergene software (version 7.0; DNASTAR, Inc.).

Selection of chemicals. Seven chemicals were selected based on four criteria: (i) fungicides currently used in Trinidad to control anthracnose in papaya, bell pepper, avocado, and mango; (ii) fungicides currently used or registered in other countries but not necessarily for the plant species of this study; and (iii) fungicides not registered for anthracnose specifically. Commercial formulations were purchased from local retailers (with the exception of Cabrio, which was supplied directly by BASF Corp.) and stored in a desiccator at $25^{\circ} \mathrm{C}$ to preserve their activity (Table 1). Commercial formulations, and not the active ingredients, were evaluated in an attempt to improve the predictive value of the in vitro sensitivity assays by ensuring that pathogen responses were based on the formulation that they would be exposed to in the field. Each chemical was prepared in dimethyl sulfoxide (DMSO, ACS reagent $\geq$ 99.9\%; Sigma-Aldrich) as stocks of $1,0.1$, and $0.01 \mathrm{~g} / \mathrm{ml}$ and then filter sterilized $(0.22-\mu \mathrm{m}$ filter). The final concentration of DMSO was maintained below $0.1 \%$ (56). The copper-based fungicide was prepared in sterile deionized water.

AA assays. Sensitivity of the isolates to different fungicides was determined by AA assays. Molten PDA was amended with stock fungicide solution to give final concentrations of $0.0,0.01,0.1,1.0$, $10.0,100.0$, and $1,000.0 \mu \mathrm{g} / \mathrm{ml}$ for each fungicide. A 4- $\mathrm{mm}^{3}$ agar block was cut from the advancing edge of an actively growing culture on PDA and placed centrally, mycelia-side down, on the surface of the AA. Plates were incubated in the dark at $25^{\circ} \mathrm{C}$ for 6 days. The radial diameter (perpendicular measurements in millimeters) was recorded for each colony and the corrected diameter (mean radial diameter minus the length of the agar block) was used 
to calculate percent relative growth $(\% \mathrm{RG}=$ [mean diameter of colony on AA/mean diameter of colony on control or nonamended agar] $\times 100)$ and percent relative growth inhibition $(\%$ RGI $=100-$ $\%$ RG) compared with the nonamended controls. Control plates consisted of a 4- $\mathrm{mm}^{3}$ agar block placed on nonamended PDA. Each isolate was plated in quadruplicate. The assays were conducted twice and the mean corrected colony diameters were used in all calculations.

AB assays. Sensitivity of the isolates to different fungicides was qualitatively determined by an $\mathrm{AB}$ assay according to the optimization procedure by Rampersad (56). Two isolates from each host species were selected (eight isolates in total). The AB test was carried out in a laminar flow hood using aseptic techniques. Particulates in canned V8 juice were first removed by filtering the juice through four layers of mira cloth (Calbiochem). The clarified supernatant was then used to prepare a $10 \%$ broth concentration using deionized water. The diluted juice was then buffered with morpholinepropanesulphonic acid (Sigma-Aldrich), the $\mathrm{pH}$ was adjusted to 7.4 at $25^{\circ} \mathrm{C}$, and the juice was then autoclaved at $121^{\circ} \mathrm{C}$ for $20 \mathrm{~min}$.

Nine-day old cultures that were actively growing on $10 \% \mathrm{~V} 8$ juice agar (10\% clarified, buffered V8 juice containing $2 \%$ BactoAgar) were used to prepare stock conidia suspensions for each isolate. The plates were flooded by adding $5 \mathrm{ml}$ of clarified, buffered $10 \%$ V8 juice broth; then, the surface of the agar was gently scraped with a sterile rubber spatula and the resulting suspension that contained dislodged conidia was filtered through two layers of sterile mira cloth. The stock conidia concentration was determined by dark-field contrast microscopy at $\times 100$ using a hemocytometer and a $10^{6}$ conidia/ml working dilution was prepared from this stock suspension. Then, $100 \mu \mathrm{l}$ of a suspension of $10^{6}$ conidia $/ \mathrm{ml}$ was added to test wells in duplicate, and stock fungicide solutions were added to give a final concentrations of each fungicide $(0.0,0.01$, $0.1,1.0,10.0$, and $100.0 \mu \mathrm{g} / \mathrm{ml}$ ). AB dye (AbD Serotec) was added as $10 \%$ of the final volume in the test wells of Nunc Maxisorp flatbottomed plates (Thermo Fisher Scientific). Plates were covered with sterile plastic plate covers, gently rotated horizontally to mix the well contents, placed in clean sealable containers lined with moistened tissue paper, and incubated in the dark at $25^{\circ} \mathrm{C}$ for $48 \mathrm{~h}$. Duplicate negative control wells contained $200 \mu \mathrm{l}$ of $10 \%$ V8 juice broth and $10 \% \mathrm{AB}$ dye only. Duplicate positive control wells contained $100 \mu \mathrm{l}$ of $10 \% \mathrm{~V} 8$ juice broth, $100 \mu \mathrm{l}$ of $10^{6}$ conidia/ml, and $10 \% \mathrm{AB}$ dye only. A chemical control plate was also prepared to ensure that the fungicides themselves did not reduce the $A B$ dye and consisted of $100 \mu \mathrm{l}$ of stock fungicide to achieve the final concentration of each fungicide, $100 \mu \mathrm{l}$ of $10 \% \mathrm{~V} 8$ juice broth, and $10 \% \mathrm{AB}$ in each test well. A positive test result was recorded as a color change from blue to pink, which indicated that the dye had been reduced due to the presence of viable conidia. A negative test result was recorded as no color change or the dye remained blue, which indicated that the dye was not reduced due to the absence of viable conidia. One mean inhibitory concentration (MIC) endpoint was visually determined and defined as the lowest concentration of fungicide that prevented a color change from blue to pink (MICblue) after $48 \mathrm{~h}$ of incubation (43). Optimal incubation time was determined by monitoring the color of the negative control wells that contained spores and $\mathrm{AB}$ only. A fluorescent pink color in these control wells was optimal and a bleached-out or faded pink appearance meant that a second redox step had occurred, which would result in lower-than-expected $\mathrm{AB}$ reduction. A purple color was considered to be a "trailing" result which would eventually turn pink after a longer incubation period (44).

Statistical analyses. All experiments were conducted twice and the mean values for both trials are presented. Statistical analyses were performed using MINITAB (v. 16 for Windows; Minitab Inc.). Replications did not serve as sources of variation and the mean values and standard error of the mean for all experiments were reported. All percentages were arcsine-transformed and data were compared by analysis of variance. Means were separated by Fisher's least significant difference test with a significance threshold of $P \leq$ 0.05 . Log concentrations of fungicide for which RG was inhibited by 50 and 90\% (log EC50 and $\log$ EC90 values, respectively) were calculated by probit analysis from log-concentration-response curves $(26,37)$. The binary response data from the $\mathrm{AB}$ tests (positive $=1$ or negative $=0$ test result for each concentration of fungicide tested) was analyzed by binary logistic regression (BLR).

\section{Results}

Isolates. In total, 118 Colletotrichum isolates were collected from the various crop hosts. $C$. gloeosporioides and $C$. truncatum isolates were identified from papaya and bell pepper collections and only C. gloeosporioides isolates were obtained from the avocado and mango collections. In papaya, $C$. gloeosporioides was more common than $C$. truncatum; however for bell pepper, $C$. truncatum was the predominant species associated with anthracnose disease of red-ripe fruit. In all, 68 representative isolates were selected for the study: 46 C. gloeosporioides isolates (12 from avocado, 12 from mango, 12 from papaya, and 10 from bell pepper,) and $22 C$. truncatum isolates (10 from papaya and 12 from bell pepper).

Comparison of percent growth inhibition for $C$. gloeosporioides isolates from all host species. For most of the fungicides and concentrations tested, there were no significant differences in \% RGI for C. gloeosporioides isolates from avocado and mango when compared separately with those from papaya and bell pepper. However, for benomyl at $1.0 \mu \mathrm{g} / \mathrm{ml}, C$. gloeosporioides isolates from avocado and mango had significantly greater \%RGI than those from papaya and bell pepper (Table 2). For benomyl at 0.1 $\mu \mathrm{g} / \mathrm{ml}$, papaya isolates had the least \%RGI compared with the other isolates which shared similar \%RGI. Conversely, for chlorothalonil at $1.0 \mu \mathrm{g} / \mathrm{ml}$ and metiram at $10.0 \mu \mathrm{g} / \mathrm{ml}, C$. gloeosporioides isolates from bell pepper had significantly higher \%RGI than the other isolates. Growth inhibition was not significantly different $(P \geq$ 0.05 ) between $C$. gloeosporioides isolates previously exposed to fungicides and those with no known history of fungicide exposure. There were also no significant interaction effects.

Comparison of percent growth inhibition for all $C$. truncatum and $C$. gloeosporioides isolates. Generally, the percent growth inhibition (\%RGI) increased with increasing concentration for all isolates and all fungicides, except for copper hydroxide. This fungicide did not inhibit mycelial growth in AA assays regardless of concentration. Hence, \%RGI values could not be calculated for this fungicide. Generally, C. truncatum isolates had significantly

Table 1. Fungicides used for in vitro amended agar and Alamar blue assays

\begin{tabular}{|c|c|c|c|c|}
\hline Trade name & Active ingredient & Manufacturer & Formulation $^{\mathrm{x}}$ & FRAC chemical class ${ }^{y}$ \\
\hline Benomyl & $50 \%$ Benomyl & VAPCO Mfg. Co. Ltd., Jordon, Israel & WP & Methyl benzimidazole carbamates \\
\hline Cabrio & $20 \%$ Pyraclostrobin & BASF Corp., Germany & EG & Quinone 0utside inhibitors \\
\hline Chlorothalonil & $29.6 \%$ Chlorothalonil & ISK Biotech Corporation, $\mathrm{OH}$, United States & WP & Chloronitriles \\
\hline Kocide & $30.7 \%$ Copper hydroxide & DuPont, United States & WP & Inorganic \\
\hline Polyram $^{z}$ & $80 \%$ Metiram & BASF Corp., Germany & DF & Dithio-carbamates \\
\hline Rizolex & $10 \%$ Tolclofos-methyl & Sumitomo Chemical Australia Pty. Ltd. & WP & Aromatic hydrocarbons \\
\hline Valete & $80 \%$ Fosetyl aluminum & VAPCO Mfg. Co. Ltd., Jordon, Israel & WP & Phosphonates \\
\hline
\end{tabular}

${ }^{\mathrm{x}} \mathrm{EC}=$ emulsifiable granule, $\mathrm{WP}=$ wettable powder, and $\mathrm{DF}=$ dust base fungicide.

y Chemical Class according to Fungicide Resistance Action Committee (FRAC) code list 2010 (30).

${ }^{\mathrm{z}}$ Polyram was not used in Alamar blue (AB) assays because it reduced the dye in the absence of spores. 
less \% RGI than C. gloeosporioides isolates. At $10.0 \mu \mathrm{g} / \mathrm{ml}, C$. truncatum isolates had significantly less \%RGI compared with $C$. gloeosporioides isolates for benomyl, tolclofos-methyl, and fosetyl-aluminum. At 100.0 and $1,000.0 \mu \mathrm{g} / \mathrm{ml}$, there was no significant difference in \% RGI for C. truncatum and C. gloeosporioides isolates for all fungicides except for benomyl and fosetylaluminum (Table 3 ).
Comparison of percent growth inhibition for only $C$. truncatum isolates. $C$. truncatum isolates reacted differently to increasing concentrations of the various fungicides depending on whether the isolates originated from pepper or papaya (Table 4). C. truncatum from pepper had generally less \%RGI than $C$. truncatum isolates from papaya. Significantly less \%RGI occurred for benomyl at concentrations $\geq 10.0 \mu \mathrm{g} / \mathrm{ml}$. C. truncatum from papaya had signifi-

Table 2. Comparison of percent relative growth inhibition (RGI) for all Colletotrichum gloeosporioides isolates tested according to host species

\begin{tabular}{|c|c|c|c|c|c|c|}
\hline \multirow[b]{2}{*}{ C. gloeosporioides isolates } & \multirow[b]{2}{*}{$N$} & \multicolumn{5}{|c|}{ RGI $(\%)$ for each fungicide concentration $(\mu \mathrm{g} / \mathrm{ml})^{\mathrm{z}}$} \\
\hline & & 0.1 & 1.0 & 10.0 & 100.0 & $1,000.0$ \\
\hline \multicolumn{7}{|l|}{ Benomyl } \\
\hline Avocado and mango & 24 & $28.9 \mathrm{~b}$ & $79.8 \mathrm{~b}$ & 82.2 & 89.1 & 99.1 \\
\hline Papaya & 12 & $16.1 \mathrm{a}$ & $80.0 \mathrm{~b}$ & 80.0 & 100.0 & 100.0 \\
\hline Pepper & 10 & $35.7 \mathrm{~b}$ & $46.4 \mathrm{a}$ & 99.9 & 99.9 & 99.9 \\
\hline$P$ value & $\ldots$ & $* 0.001$ & $* 0.021$ & 0.169 & 0.423 & $\ldots$ \\
\hline \multicolumn{7}{|l|}{ Pyraclostrobin } \\
\hline Avocado and mango & 24 & 17.9 & 30.1 & 34.1 & 90.2 & 99.1 \\
\hline Papaya & 12 & 31.4 & 35.6 & 42.0 & 100.0 & 100.0 \\
\hline Pepper & 10 & 27.0 & 38.5 & 36.1 & 100.0 & 100.0 \\
\hline$P$ value & $\ldots$ & 0.174 & 0.944 & 0.817 & 0.839 & $\ldots$ \\
\hline \multicolumn{7}{|l|}{ Chlorothalonil } \\
\hline Avocado and mango & 24 & $10.9 \mathrm{~b}$ & 27.7 & 67.5 & 90.2 & 99.1 \\
\hline Papaya & 12 & $0.0 \mathrm{a}$ & 60.6 & 85.0 & 100.0 & 100.0 \\
\hline Pepper & 10 & $7.7 \mathrm{~b}$ & 27.6 & 81.1 & 100.0 & 100.0 \\
\hline$P$ value & $\ldots$ & $* 0.033$ & 0.057 & 0.785 & 0.839 & $\ldots$ \\
\hline \multicolumn{7}{|l|}{ Metiram } \\
\hline Avocado and mango & 24 & 10.5 & 21.3 & 33.8 & 90.8 & 100.0 \\
\hline Papaya & 12 & 4.4 & 30.9 & 69.0 & 100.0 & 100.0 \\
\hline Pepper & 10 & 9.9 & 28.8 & 37.0 & 100.0 & 100.0 \\
\hline$P$ value & $\ldots$ & 0.489 & 0.814 & 0.064 & 0.838 & $\ldots$ \\
\hline \multicolumn{7}{|l|}{ Tolclofos-methyl } \\
\hline Avocado and mango & 24 & 9.1 & 25.1 & 59.3 & 91.9 & 99.0 \\
\hline Papaya & 12 & 3.2 & 30.5 & 72.0 & 100.0 & 100.0 \\
\hline Pepper & 10 & 5.0 & 19.1 & 81.1 & 99.9 & 99.9 \\
\hline$P$ value & $\ldots$ & 0.624 & 0.882 & 0.799 & 0.398 & $\ldots$ \\
\hline \multicolumn{7}{|l|}{ Fosetyl-aluminum } \\
\hline Avocado and mango & 24 & 2.8 & 8.6 & 24.1 & 89.0 & 99.0 \\
\hline Papaya & 12 & 0.0 & 0.5 & 11.5 & 90.3 & 100.0 \\
\hline Pepper & 10 & 4.2 & 3.8 & 27.5 & 99.9 & 99.9 \\
\hline$P$ value & $\ldots$ & 0.139 & 0.202 & 0.064 & 0.552 & $\ldots$ \\
\hline
\end{tabular}

z Asterisk (*) indicates $P \leq 0.05$.

Table 3. Comparison of percent relative growth inhibition (RGI) for all Colletotrichum truncatum and C. gloeosporioides isolates tested

\begin{tabular}{|c|c|c|c|c|c|c|}
\hline \multirow[b]{2}{*}{ Isolates } & \multirow[b]{2}{*}{$N$} & \multicolumn{5}{|c|}{ RGI $(\%)$ for each fungicide concentration $(\mu \mathrm{g} / \mathrm{ml})^{\mathrm{z}}$} \\
\hline & & 0.1 & 1.0 & 10.0 & 100.0 & $1,000.0$ \\
\hline \multicolumn{7}{|l|}{ Benomyl } \\
\hline All C. gloeosporioides & 46 & 22.0 & 78.9 & 91.2 & 99.9 & 99.9 \\
\hline All C. truncatum & 22 & 13.7 & 17.7 & 16.2 & 63.0 & 95.1 \\
\hline$P$ value & $\ldots$ & 0.300 & $\leq 0.001$ & $\leq 0.001$ & $\leq 0.001$ & $\leq 0.001$ \\
\hline \multicolumn{7}{|l|}{ Pyraclostrobin } \\
\hline All C. gloeosporioides & 46 & 21.1 & 32.9 & 37.1 & 100.0 & 100.0 \\
\hline All C. truncatum & 22 & 12.6 & 19.0 & 27.6 & 100.0 & 100.0 \\
\hline$P$ value & $\ldots$ & 0.100 & $\leq 0.001$ & $\leq 0.001$ & $\ldots$ & $\ldots$ \\
\hline \multicolumn{7}{|l|}{ Chlorothalonil } \\
\hline All C. gloeosporioides & 46 & 5.3 & 35.0 & 79.6 & 100.0 & 100.0 \\
\hline All C. truncatum & 22 & 5.0 & 28.1 & 82.6 & 100.0 & 100.0 \\
\hline$P$ value & $\ldots$ & 0.700 & 0.200 & 0.500 & $\ldots$ & $\ldots$ \\
\hline \multicolumn{7}{|l|}{ Metiram } \\
\hline All C. gloeosporioides & 46 & 7.3 & 24.2 & 44.0 & 100.0 & 100.0 \\
\hline All C. truncatum & 22 & 7.8 & 34.0 & 40.2 & 100.0 & 100.0 \\
\hline$P$ value & $\ldots$ & 0.800 & 0.500 & 0.500 & $\ldots$ & $\ldots$ \\
\hline \multicolumn{7}{|l|}{ Tolclofos-methyl } \\
\hline All C. gloeosporioides & 46 & 4.0 & 20.9 & 78.2 & 99.9 & 99.9 \\
\hline All C. truncatum & 22 & 15.0 & 30.3 & 87.9 & 99.9 & 99.9 \\
\hline$P$ value & $\ldots$ & $\leq 0.001$ & 0.100 & $\leq 0.001$ & 0.300 & 0.300 \\
\hline \multicolumn{7}{|l|}{ Fosetyl-aluminum } \\
\hline All C. gloeosporioides & 46 & 1.8 & 3.5 & 19.3 & 97.4 & 99.9 \\
\hline All C. truncatum & 22 & 4.0 & 3.5 & 6.9 & 23.1 & 99.9 \\
\hline$P$ value & $\ldots$ & 0.400 & 0.900 & $\leq 0.001$ & 0.001 & 0.300 \\
\hline
\end{tabular}


cantly less \%RGI than $C$. truncatum from pepper in the presence of pyraclostrobin and fosetyl-aluminum at $\geq 10.0 \mu \mathrm{g} / \mathrm{ml}$.

Comparison of percent growth inhibition for $C$. truncatum and $\boldsymbol{C}$. gloeosporioides isolates from papaya. $C$. gloeosporioides isolates from papaya had generally higher \%RGI than C. truncatum isolates for all concentrations tested for pyraclostrobin, chlorothalonil, and fosetyl-aluminum. Significant differences were recorded at concentrations $\geq 10.0 \mu \mathrm{g} / \mathrm{ml}$. Significantly less $\%$ RGI were obtained for benomyl for C. gloeosporioides isolates (Table 5).

Comparison of percent growth inhibition for $C$. truncatum and $C$. gloeosporioides isolates from pepper. $C$. gloeosporioides isolates from pepper had generally higher \%RGI than $C$. truncatum isolates for all concentrations tested for most fungicides (Table 6). Significantly higher \%RGI was recorded for benomyl and fosetylaluminum at $10.0 \mu \mathrm{g} / \mathrm{ml}$. Both Colletotrichum spp. reacted equally to all tested concentrations of pyraclostrobin, chlorothalonil, and metiram.

Comparison of $\log$ EC50 and $\log$ EC90 values. Log EC50 and EC90 values were calculated for all isolates according to fungicide (Table 7). Colletotrichum spp. and type of fungicide had significant effects on the calculated log EC values $(P \leq 0.0001$ for both variables). When $\log$ EC values were compared for only $C$. gloeosporioides isolates, there were no significant differences $(P=0.136$ and 0.231 for $\log$ EC50 and $\log$ EC90, respectively). Similarly, for only C. truncatum isolates, there were no significant differences in $\log$ EC values $(P=0.311$ and 0.504 for $\log$ EC50 and $\log$ EC90, respectively). There was no gradient response to increasing concentrations of benomyl (\%RGI was absolute for all C. gloeosporioides isolates at $\geq 10.0 \mu \mathrm{g} / \mathrm{ml}$ ), and copper hydroxide (\%RGI was effectively zero for all isolates at all concentrations tested); hence,

Table 4. Comparison of percent growth inhibition (RGI) for only Colletotrichum truncatum isolates from pepper and papaya

\begin{tabular}{|c|c|c|c|c|c|c|}
\hline \multirow[b]{2}{*}{ C. truncatum isolates } & \multirow[b]{2}{*}{$N$} & \multicolumn{5}{|c|}{ RGI $(\%)$ for each fungicide concentration $(\mu \mathrm{g} / \mathrm{ml})^{\mathrm{z}}$} \\
\hline & & 0.1 & 1.0 & 10.0 & 100.0 & $1,000.0$ \\
\hline \multicolumn{7}{|l|}{ Benomyl } \\
\hline Pepper & 12 & 11.1 & 11.1 & 8.8 & 32.1 & 91.0 \\
\hline Papaya & 10 & 16.7 & 25.5 & 25.2 & 100.0 & 100.0 \\
\hline$P$ value & $\ldots$ & $\leq 0.001$ & $\leq 0.001$ & $\leq 0.001$ & $\leq 0.001$ & $\leq 0.001$ \\
\hline \multicolumn{7}{|l|}{ Pyraclostrobin } \\
\hline Pepper & 12 & 15.9 & 28.7 & 31.8 & 100.0 & 100.0 \\
\hline Papaya & 10 & 8.7 & 7.4 & 22.5 & 100.0 & 100.0 \\
\hline$P$ value & $\ldots$ & 0.700 & $\leq 0.001$ & 0.100 & $>0.05$ & $>0.05$ \\
\hline \multicolumn{7}{|l|}{ Chlorothalonil } \\
\hline Pepper & 12 & 7.9 & 13.8 & 84.1 & 100.0 & 100.0 \\
\hline Papaya & 10 & 1.4 & 45.3 & 80.8 & 100.0 & 100.0 \\
\hline$P$ value & $\ldots$ & 0.300 & $\leq 0.001$ & 0.500 & $\ldots$ & $\ldots$ \\
\hline \multicolumn{7}{|l|}{ Metiram } \\
\hline Pepper & 12 & 8.3 & 41.7 & 44.7 & 100.0 & 100.0 \\
\hline Papaya & 10 & 7.2 & 24.7 & 34.8 & 100.0 & 100.0 \\
\hline$P$ value & $\ldots$ & 0.900 & 0.200 & 0.300 & $\ldots$ & $\ldots$ \\
\hline \multicolumn{7}{|l|}{ Tolclofos-methyl } \\
\hline Pepper & 12 & 19.0 & 30.2 & 83.2 & 99.9 & 99.9 \\
\hline Papaya & 10 & 10.2 & 30.4 & 93.7 & 100.0 & 100.0 \\
\hline$P$ value & $\ldots$ & 0.200 & 1.000 & 0.100 & $\ldots$ & $\ldots$ \\
\hline \multicolumn{7}{|l|}{ Fosetyl-aluminum } \\
\hline Pepper & 12 & 0.0 & 1.2 & 10.3 & 28.6 & 99.9 \\
\hline Papaya & 10 & 8.8 & 6.2 & 2.8 & 16.5 & 100.0 \\
\hline$P$ value & $\ldots$ & $\leq 0.001$ & 0.100 & $\leq 0.001$ & $\leq 0.001$ & $\ldots$ \\
\hline
\end{tabular}

Table 5. Comparison of percent growth inhibition (RGI) for only Colletotrichum truncatum and C. gloeosporioides isolates from papaya

\begin{tabular}{|c|c|c|c|c|c|c|}
\hline \multirow[b]{2}{*}{ Isolates, papaya } & \multirow[b]{2}{*}{$N$} & \multicolumn{5}{|c|}{ RGI (\%) for each fungicide concentration $(\mu \mathrm{g} / \mathrm{ml})^{\mathrm{z}}$} \\
\hline & & 0.1 & 1.0 & 10.0 & 100.0 & $1,000.0$ \\
\hline \multicolumn{7}{|l|}{ Benomyl } \\
\hline C. truncatum & 10 & 0.0 & 25.1 & 24.8 & 100.0 & 100.0 \\
\hline C. gloeosporioides & 12 & 16.1 & 80.0 & 80.0 & 100.0 & 100.0 \\
\hline$P$ value & $\ldots$ & $\leq 0.001$ & $\leq 0.001$ & $\leq 0.001$ & $\ldots$ & $\ldots$ \\
\hline \multicolumn{7}{|l|}{ Pyraclostrobin } \\
\hline C. truncatum & 10 & 8.7 & 7.4 & 22.5 & 100.0 & 100.0 \\
\hline C. gloeosporioides & 12 & 31.4 & 35.6 & 42.0 & 100.0 & 100.0 \\
\hline$P$ value & $\ldots$ & $\leq 0.001$ & $\leq 0.001$ & $\leq 0.001$ & $\ldots$ & $\ldots$ \\
\hline \multicolumn{7}{|l|}{ Chlorothalonil } \\
\hline C. truncatum & 10 & 1.4 & 45.3 & 80.8 & 100.0 & 100.0 \\
\hline C. gloeosporioides & 12 & 0.0 & 60.6 & 85.0 & 100.0 & 100.0 \\
\hline$P$ value & $\ldots$ & 0.300 & 0.300 & 0.400 & $\ldots$ & $\ldots$ \\
\hline \multicolumn{7}{|l|}{ Metiram } \\
\hline C. truncatum & 10 & 7.2 & 24.7 & 34.8 & 100.0 & 100.0 \\
\hline C. gloeosporioides & 12 & 4.4 & 30.9 & 69.0 & 100.0 & 100.0 \\
\hline$P$ value & $\ldots$ & 0.500 & 0.700 & 0.100 & $\ldots$ & $\ldots$ \\
\hline \multicolumn{7}{|l|}{ Tolclofos-methyl } \\
\hline C. truncatum & 10 & 10.2 & 30.4 & 93.7 & 100.0 & 100.0 \\
\hline C. gloeosporioides & 12 & 3.2 & 30.5 & 72.0 & 100.0 & 100.0 \\
\hline$P$ value & $\ldots$ & 0.100 & 0.800 & 0.100 & $\ldots$ & $\ldots$ \\
\hline \multicolumn{7}{|l|}{ Fosetyl-aluminum } \\
\hline C. truncatum & 10 & 8.8 & 6.2 & 2.8 & 16.5 & 100.0 \\
\hline C. gloeosporioides & 12 & 0.0 & 0.5 & 11.5 & 90.3 & 100.0 \\
\hline$P$ value & $\ldots$ & $\leq 0.001$ & 0.100 & $\leq 0.001$ & $\leq 0.001$ & $\ldots$ \\
\hline
\end{tabular}


regression analyses could not be conducted for these fungicides and, subsequently, log EC values could not be calculated for the isolates.

Correlation of EC values for strobilurin fungicide. Correlation analyses of $\log$ EC50 and $\log$ EC90 values of all the isolates revealed a nonsignificant association for pyraclostrobin (log EC50 $r^{2}=0.305, P=0.079 ; \log$ EC90 $\left.r^{2}=0.329, P=0.057\right)$. Neither were the correlations significant for $\log$ EC values for only $C$. gloeosporioides isolates ( $\log$ EC50 $r^{2}=0.328, P=0.126 ; \log$ EC90 $\left.r^{2}=0.297, P=0.169\right)$ nor for $\log$ EC values for only $C$. truncatum isolates $\left(\log\right.$ EC50 $r^{2}=0.187, P=0.581 ; \log$ EC90 $r^{2}=$ $0.348, P=0.295$ )

AB assays. $A B$ assays were conducted to determine the effects of different classes of fungicides on spore viability of Colletotrichum isolates. Generally, positive $\mathrm{AB}$ test results occurred at the lower concentrations of fungicides used in the assay. The visually determined MIC-blue values for each isolate according to fungicide were recorded (Fig. 1; Table 8). Values could not be obtained for metiram because this fungicide caused a reduction of the dye in the absence of any spores. A significantly higher percentage of positive $A B$ test results was obtained for papaya and pepper isolates when compared with all other isolates for all fungicides tested, except for chlorothalonil (Table 9). BLR analysis was significant $(P=0.001$; Table 10$)$ and adequately described the relationship between the test response (positive or negative $A B$ test result) and the predictor variables in the data set because the Pearson, Deviance, and Hosmer-Lemenshow tests gave very large $P$ values $(P>0.990)$. Species and fungicide concentration were significant $(P \leq 0.001$ for both) predictors of whether a positive $\mathrm{AB}$ test result would be obtained. Among the $C$. gloeosporioides isolates, the probability of obtaining a positive $\mathrm{AB}$ test result was significantly higher for isolates PAP-41-papaya $(P \leq 0.001)$, SPE-

Table 6. Comparison of percent growth inhibition (RGI) for only Colletotrichum truncatum and C. gloeosporioides isolates from pepper

\begin{tabular}{|c|c|c|c|c|c|c|}
\hline \multirow[b]{2}{*}{ Isolates, pepper } & \multirow[b]{2}{*}{$N$} & \multicolumn{5}{|c|}{ RGI $(\%)$ for each fungicide concentration $(\mu \mathrm{g} / \mathrm{ml})^{\mathrm{z}}$} \\
\hline & & 0.1 & 1.0 & 10.0 & 100.0 & $1,000.0$ \\
\hline \multicolumn{7}{|l|}{ Benomyl } \\
\hline C. truncatum & 12 & 11.1 & 11.1 & 8.8 & 32.1 & 91.0 \\
\hline C. gloeosporioides & 10 & 35.7 & 46.4 & 99.9 & 99.9 & 99.9 \\
\hline$P$ value & $\ldots$ & $\leq 0.001$ & $\leq 0.001$ & $\leq 0.0001$ & $\leq 0.001$ & $\leq 0.001$ \\
\hline \multicolumn{7}{|l|}{ Pyraclostrobin } \\
\hline C. truncatum & 12 & 15.9 & 28.7 & 31.8 & 100.0 & 100.0 \\
\hline C. gloeosporioides & 10 & 27.0 & 38.5 & 36.1 & 100.0 & 100.0 \\
\hline$P$ value & $\ldots$ & 0.200 & 0.100 & 0.600 & $\ldots$ & $\ldots$ \\
\hline \multicolumn{7}{|l|}{ Chlorothalonil } \\
\hline C. truncatum & 12 & 7.9 & 13.8 & 84.1 & 100.0 & 100.0 \\
\hline C. gloeosporioides & 10 & 7.7 & 27.6 & 81.1 & 100.0 & 100.0 \\
\hline$P$ value & $\ldots$ & 0.900 & 0.100 & 0.400 & $\ldots$ & $\ldots$ \\
\hline \multicolumn{7}{|l|}{ Metiram } \\
\hline C. truncatum & 12 & 8.3 & 41.7 & 44.7 & 100.0 & 100.0 \\
\hline C. gloeosporioides & 10 & 9.9 & 28.8 & 37.0 & 100.0 & 100.0 \\
\hline$P$ value & $\ldots$ & 0.600 & 0.100 & 0.977 & $\ldots$ & $\ldots$ \\
\hline \multicolumn{7}{|l|}{ Tolclofos-methyl } \\
\hline C. truncatum & 12 & 19.0 & 30.2 & 83.2 & 99.9 & 99.9 \\
\hline C. gloeosporioides & 10 & 5.0 & 19.1 & 81.1 & 99.9 & 99.9 \\
\hline$P$ value & $\ldots$ & $\leq 0.001$ & $\leq 0.001$ & 0.989 & $\ldots$ & $\ldots$ \\
\hline \multicolumn{7}{|l|}{ Fosetyl-aluminum } \\
\hline C. truncatum & 12 & 0.0 & 1.2 & 10.3 & 28.6 & 99.9 \\
\hline C. gloeosporioides & 10 & 4.2 & 3.8 & 27.5 & 99.9 & 99.9 \\
\hline$P$ value & $\ldots$ & $\leq 0.001$ & 0.400 & $\leq 0.001$ & $\leq 0.001$ & $\ldots$ \\
\hline
\end{tabular}

Table 7. Means and ranges of 50 and $90 \%$ effective concentration ( $\log$ EC50 and EC90) values for all isolates ${ }^{2}$

\begin{tabular}{|c|c|c|c|c|}
\hline \multirow[b]{2}{*}{ Isolates } & \multicolumn{2}{|c|}{$\log$ EC50 } & \multicolumn{2}{|c|}{$\log$ EC90 } \\
\hline & Mean & Range & Mean & Range \\
\hline \multicolumn{5}{|l|}{ Pyraclostrobin } \\
\hline All isolates & 0.65 & $0.01-1.00$ & 2.14 & $1.00-1.69$ \\
\hline Only C. gloeosporioides & 0.39 & $0.01-0.42$ & 1.38 & $1.00-1.68$ \\
\hline Only C. truncatum & 0.53 & $0.09-1.00$ & 1.51 & $1.27-1.69$ \\
\hline \multicolumn{5}{|l|}{ Chlorothalonil } \\
\hline All isolates & 0.81 & $0.01-1.14$ & 2.04 & $0.8-2.31$ \\
\hline Only C. gloeosporioides & 0.46 & $0.01-0.95$ & 1.35 & $0.8-2.31$ \\
\hline Only C. truncatum & 0.69 & $0.23-1.14$ & 1.39 & $1.23-1.73$ \\
\hline \multicolumn{5}{|l|}{ Metiram } \\
\hline All isolates & 0.86 & $0.01-1.29$ & 2.23 & $0.64-1.94$ \\
\hline Only C. gloeosporioides & 0.55 & $0.01-1.29$ & 1.48 & $0.64-1.88$ \\
\hline Only C. truncatum & 0.63 & $0.01-1.13$ & 1.51 & $1.10-1.94$ \\
\hline \multicolumn{5}{|l|}{ Tolclofos-methyl } \\
\hline All isolates & 0.51 & $0.09-1.05$ & 1.99 & $0.68-3.05$ \\
\hline Only C. gloeosporioides & 0.48 & $0.4-1.05$ & 1.46 & $0.73-3.05$ \\
\hline Only C. truncatum & 0.07 & $0.09-0.71$ & 1.06 & $0.68-1.93$ \\
\hline \multicolumn{5}{|l|}{ Fosetyl-aluminum } \\
\hline All isolates & 2.03 & $0.30-2.32$ & 3.22 & $1.47-3.29$ \\
\hline Only C. gloeosporioides & 1.16 & $0.42-1.56$ & 1.85 & $1.47-3.00$ \\
\hline Only $C$. truncatum & 1.75 & $0.30-2.32$ & 2.73 & $2.41-3.29$ \\
\hline
\end{tabular}

${ }^{\mathrm{z}}$ Log EC values could not be determined for benomyl and copper hydroxide because a linear range was not obtained with respect to inhibition of growth on amended agar tests. 
3A-pepper $(P \leq 0.001)$, and Man-Sc-mango $(P=0.008)$. Of the $C$. truncatum isolates tested, a significantly higher probability $(P \leq$ 0.001 ) of obtaining a positive AB test result was identified for isolate SPE-13A from pepper. The calculated odds ratio for these isolates also indicated a very high probability of obtaining a positive $A B$ test result. All fungicides had a similar inhibitory effect on isolates and species at increasing concentrations. Interaction effects were nonsignificant.

Molecular characterization of benzimidazole-resistant isolates. Sequences of the $\beta$-tubulin amplicons (475 bp in length) of two $C$. gloeosporioides isolates each from the four host species and two $C$. truncatum isolates each from papaya and bell pepper were compared with cognate sequences of the reference isolate, $C$. gloeosporioides f. sp. aeschynomene (Fig. 2). Sequence alignments between $C$. gloeosporioides isolates and C. gloeosporioides $\mathrm{f}$. sp. aeschynomene revealed no base substitutions at any of the codons, including 198, 199, 200, and 240. Sequences of the C. gloeosporioides isolates corresponded with nucleotide positions 1,183 to 1,551 of the cognate $\beta$-tubulin sequence of $C$. gloeosporioides $\mathrm{f}$. sp. aeschynomene.

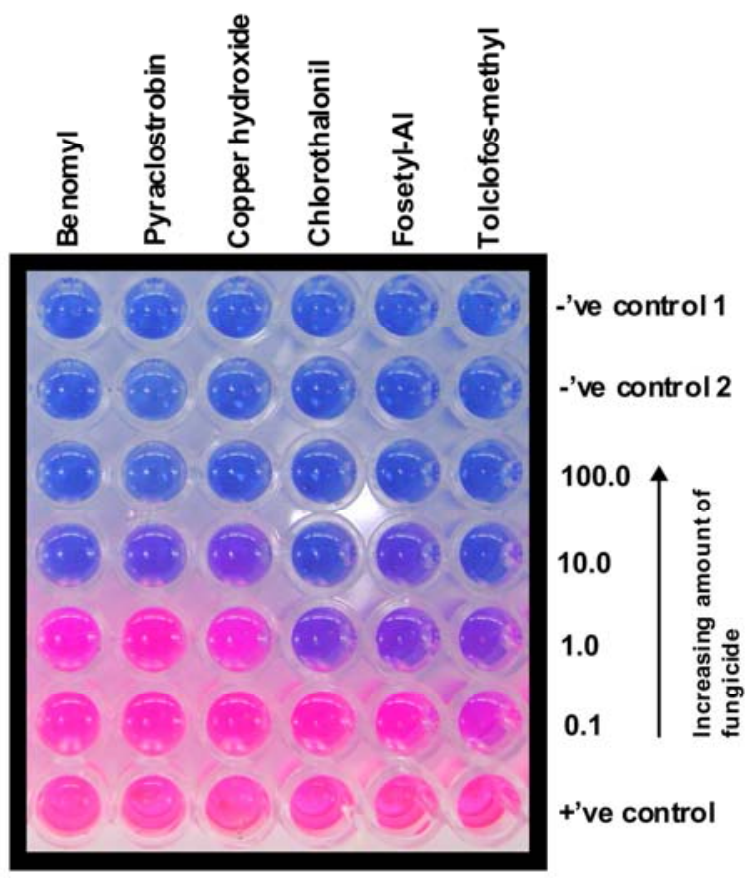

Fig. 1. Assessment of spore response to different concentrations of fungicides based on qualitative analysis of reduction of the Alamar blue dye. The spore response of a representative isolate (Colletotrichum gloeosporioides, PAP-41) is shown. Concentration of fungicide was in microliters per millimeter. Negative controls were $1,100 \mu \mathrm{l}$ of media and $10 \mu \mathrm{l}$ of Alamar blue redox dye only (no spores) and 2, $100 \mu \mathrm{l}$ of fungicide (final concentration of $1.0 \mu \mathrm{g} / \mathrm{ml}$ ) and $10 \mu \mathrm{l}$ of Alamar blue redox dye only (no spores). The positive control was $100 \mu \mathrm{l}$ of stock spore suspension at $10^{6} \mathrm{conidia} / \mathrm{ml}$ and $10 \mu \mathrm{l}$ of Alamar blue dye only (no fungicide).
PCR amplification of $C$. truncatum isolates from papaya and bell pepper produced amplicons of expected band size for only $C$. truncatum isolates from papaya. No amplicons were obtained for bell pepper isolates, which may suggest mutation changes in primer annealing sites. Sequences of the $C$. truncatum isolates corresponded to nucleotide positions 1,144 to 1,561 of the cognate $\beta$ tubulin sequence of $C$. gloeosporioides f. sp. aeschynomene. Sequence alignments between $C$. truncatum isolates and $C$. gloeosporioides $\mathrm{f}$. sp. aeschynomene revealed base substitutions that led to two codon changes; codons 154 (K-R: lysine-arginine), and 170 (V-G: valine-glycine). The relationship between the benzimidazole (BEN)-resistant phenotype of these $C$. truncatum isolates and the identified codon changes in the $\beta$-tubulin gene sequence needs further verification because no other similar studies were previously carried out for this Colletotrichum sp.

\section{Discussion}

This comparative study evaluated the sensitivities of Colletotrichum isolates from different host species to various fungicides with different modes of action utilizing two methods that assess two fitness parameters: the conventional AA test, which monitors mycelial growth, and a novel bioassay that is based on the ability of $\mathrm{AB}$ viability dye to react to certain respiratory activities of fungal spores, which is indicative of spore viability. According to AA tests, $\log$ EC values and RGI were a function of $\mathrm{Col}$ letotrichum sp. and type of fungicide. Results also indicated that Colletotrichum spp., isolate, type, and concentration of fungicide were significant variables that affected whether a positive AB test result would be obtained. When the results of both techniques were compared, both were useful at discerning chemicals that effectively reduced mycelial growth or spore viability according to Colletotrichum spp.

Developing an appropriate assay that is tailored to meet specific requirements can be challenging. Understanding what the assay has to measure, the cell type to be used in the study, the need for end-point determinations, the correlation between measurement and cell viability (number of live cells), and the potential limitations of assay chemistries are all important for either manual or automated high-throughput platforms. Some assays may be more suited to certain cell lines or only primary cell lines or some may be more applicable to adherent cells than cell suspensions. Another consideration when using metabolic assays is that metabolic activity can vary depending on the life cycle of a given cell and the cell type $(41,55)$. In addition, assay responsiveness is influenced by a number of factors, including the culture medium, cell density, evaporation, edge effects (the microtiter plate format), temperature, and $\mathrm{pH}$; interactions between the culture media and test compound components, assay chemistry, dose, and exposure; sensitivity and linearity of the assay; reagent toxicity; stability for time-course monitoring; instrumentation availability (spectrophotometer, fluorometer, and luminometer); total cost of the assay; safety to the user and the environment; reproducibility of the data and level of intra- and inter-laboratory agreement; and, finally, whether the in vitro data can reliably predict meaningful in vivo effects. It is also worth noting that the data derived from these assays represent an

Table 8. Mean inhibitory concentration-blue (MIC-blue) values according to an Alamar blue assay ${ }^{z}$

\begin{tabular}{|c|c|c|c|c|c|c|}
\hline Isolate & Benomyl & Pyraclostrobin & Chlorothalonil & Copper hydroxide & Tolclofos-methyl & Fosetyl-aluminum \\
\hline PAP-14 (C. truncatum) & 10.0 & 10.0 & 1.0 & 10.0 & 10.0 & 100.0 \\
\hline PAP-41 (C. gloeosporioides) & 10.0 & 10.0 & 10.0 & 100.0 & 10.0 & 100.0 \\
\hline SPE-13B (C. truncatum) & 10.0 & 10.0 & 10.0 & 10.0 & 10.0 & 100.0 \\
\hline SPE-3A (C. gloeosporioides) & 10.0 & 10.0 & 10.0 & 10.0 & 10.0 & 100.0 \\
\hline Avo1 (C. gloeosporioides) & 1.0 & 10.0 & 1.0 & 1.0 & 1.0 & 10.0 \\
\hline Avo2 (C. gloeosporioides) & 1.0 & 10.0 & 1.0 & 1.0 & 10.0 & 100.0 \\
\hline Man-Sc (C. gloeosporioides) & 10.0 & 10.0 & 1.0 & 10.0 & 0.1 & 10.0 \\
\hline Man-Lc (C. gloeosporioides) & 10.0 & 10.0 & 1.0 & 10.0 & 10.0 & 10.0 \\
\hline
\end{tabular}

${ }^{\mathrm{z}}$ MIC-blue was defined as the lowest concentration of fungicide that prevented a color change from blue (negative test result) to pink (positive test result) after 48 -h incubation at $25^{\circ} \mathrm{C}$. Polyram caused a reduction of the dye and a color change from blue to pink in the absence of any spores in chemical control wells; hence, MIC-blue values could not be obtained for any of the isolates. 
estimated signal of the entire population in vitro and may not always reflect an in vivo response.

The optimum $\mathrm{pH}$ of the $\mathrm{AB}$ assay is between 7.0 and 7.4, which means that the liquid culture medium must be clarified and buffered with phosphate. The optimum temperature is $37^{\circ} \mathrm{C}$ and plates must be sealed to prevent evaporation. It is critical to run the assays at a uniform temperature to ensure reproducibility across a single plate. Stacking large numbers of assay plates together in close proximity should be avoided to ensure temperature equilibration. The redox indicator is also photosensitive and the incubations must be done in the dark. The culture medium and the test compound must be nonreducing. It is also preferred that the culture medium be synthetic and defined; however, it also must allow sufficient growth so that stimulatory or inhibitory effects of test compounds are not exaggerated. Proper negative and positive controls are required to test whether compounds being measured have an effect on the assay chemistry or result in artifacts. The duration of incubation and cell density must be empirically determined because too-low cell density means slower growth and lower-thanexpected levels of dye reduction. The optimal end point of the assay depends on the cell density used; generally, it is recommended that the cells be in the exponential stage of growth. Quenching of fluorescence or bleaching out of the pink color of the reduced state of the dye occurs after prolonged incubation times due to the formation of a colorless product called dihydroresorufin. Exhaustion of the buffering capacity of the dye's formulation may explain the formation of this product (AbD Serotec). Apart from prolonged incubation times, $10 \%$ fetal bovine serum and bovine serum albumin may also cause quenching of the assay $(32,48)$. Phenol red does not affect assay chemistry except to shift all values 0.03 units higher than without phenol red. Microbial debris and contamination will reduce the redox indicator and lead to false results; hence, the assay must be set up under aseptic conditions and the medium may require supplementation with antibiotics (1). Originally, $A B$ as a redox indicator was thought to be reduced by mitochondrial enzymes. However, other enzymes may be able to reduce $\mathrm{AB}$ such as the diaphorases (dihydrolipoamine dehydrogenase; EC 1.8.1.4.) (42), NAD(P)H:quinone oxidoreductase (EC 1.6.99.2) (12), and flavin reductase (EC 1.6.99.1) (16), which can be found in the cytoplasm (EC 1.6.99.1) and mitochondria (EC 1.6.99.2). Hence, a decline in $\mathrm{AB}$ reduction indicates an impairment of cellular metabolism rather than specific mitochondrial dysfunction through interruption of electron transport.

Rampersad (56) demonstrated a quantitative application of the $\mathrm{AB}$ assay by determining the percent reduction of the $\mathrm{AB}$ dye deduced from the spectrophotometric relationship between the corrected recorded absorbance at two wavelengths for the oxidized and reduced forms of the dye in test wells and the molar extinction coefficients of the dye at these wavelengths. This study demonstrated a qualitative application of the assay where presence or absence of a color change in the dye indicated sensitivity to different concentrations of various fungicides. The $\mathrm{AB}$ assay detected that $C$. gloeosporioides isolates from papaya and pepper and one from mango were more likely to give a positive $\mathrm{AB}$ test result than the other isolates according to BLR analyses. When the overall combined percentage of positive $\mathrm{AB}$ test results obtained for each fungicide over the range of concentrations tested were compared, there was a significantly higher percentage of positive $A B$ test results for papaya and pepper isolates, with the exception of chlorothalonil. Intensive year-round production of papaya and pepper with concomitant chemical use would have exposed these isolates to a number of chemicals, more so than isolates from mango and avocado hosts, which are seasonally produced with limited to no chemical use. The $\mathrm{AB}$ results also suggested a higher sensitivity of fungal spores to copper hydroxide and pyraclostrobin when compared with their effects on hyphal extension. This can be explained by the modes of action of these fungicides and greater sensitivity of the $\mathrm{AB}$ assay in detecting spore viability (e.g., spore germination is an energetically demanding stage of fungal development and is particularly sensitive to strobilurin fungicides and copper chemistries; 69).

BEN fungicides inhibit microtubule formation and assembly. Single-site activity facilitates development of resistance to BENs

Table 9. Percentage of Colletotrichum gloeosporioides isolates with a positive Alamar blue test result according to fungicide ${ }^{\mathrm{y}}$

\begin{tabular}{lccccc}
\hline & \multicolumn{5}{c}{ Percentage + test results } \\
\cline { 2 - 6 } Isolates from & Pyraclostrobin & Chlorothalonil & Copper hydroxide & Tolclofos-methyl & Fosetyl-aluminum \\
\hline Papaya and pepper & 60 & 40 & 70 & 50 & 60 \\
Avocado and mango & 40 & 40 & 30 & 30 & 0.003 \\
$P$ value & 0.004 & $\ldots$ & 0.001 & 40 & 0.004 \\
\hline
\end{tabular}

${ }^{y}$ Percentages to the nearest whole number from tests conducted twice.

${ }^{\mathrm{z}} P \leq 0.05$.

Table 10. Binary logistic regression of responses obtained from an Alamar blue assay ${ }^{z}$

\begin{tabular}{|c|c|c|c|c|c|c|c|}
\hline \multirow[b]{2}{*}{ Predictor } & \multirow[b]{2}{*}{ Coeff } & \multirow[b]{2}{*}{ SE Coef } & \multirow[b]{2}{*}{$\mathbf{Z}$} & \multirow[b]{2}{*}{$\boldsymbol{P}$} & \multirow[b]{2}{*}{ Odds ratio } & \multicolumn{2}{|c|}{$95 \% \mathrm{CI}$} \\
\hline & & & & & & Lower & Upper \\
\hline Constant & 6.3504 & 1.1013 & 5.77 & 0.000 & & & \\
\hline Log concentration & -3.4634 & 0.3842 & -9.02 & 0.000 & 0.03 & 0.01 & 0.07 \\
\hline \multicolumn{8}{|l|}{ Species } \\
\hline Colletotrichum gloeosporioides isolate & -5.3581 & 0.9889 & -5.42 & 0.000 & 0.00 & 0.00 & 0.03 \\
\hline Avo2 & 1.5775 & 0.8133 & 1.94 & 0.052 & 4.84 & 0.98 & 23.83 \\
\hline Man-Lc & 1.5772 & 0.8133 & 1.91 & 0.025 & 4.84 & 0.98 & 23.83 \\
\hline Man-Sc & 2.2085 & 0.8309 & 2.66 & 0.008 & 9.10 & 1.79 & 46.39 \\
\hline PAP-14 & 5.3581 & 0.9889 & 5.43 & 0.000 & 212.32 & 30.56 & $1,475.15$ \\
\hline PAP-41 & 4.0988 & 0.9129 & 4.49 & 0.000 & 60.26 & 10.07 & 360.66 \\
\hline SPE-13B & 1.2618 & 0.8065 & 1.56 & 0.118 & 3.53 & 0.76 & 17.16 \\
\hline SPE-3A & 3.7845 & 0.8965 & 4.22 & 0.000 & 44.01 & 7.59 & 255.09 \\
\hline \multicolumn{8}{|l|}{ Fungicide } \\
\hline Tolclofos-methyl & -0.8855 & 0.9450 & -0.94 & 0.349 & 0.41 & 0.06 & 2.63 \\
\hline Copper hydroxide & -1.7572 & 0.9537 & -1.84 & 0.050 & 0.17 & 0.03 & 1.12 \\
\hline Benomyl & -1.7572 & 0.9538 & -1.84 & 0.065 & 0.17 & 0.03 & 1.12 \\
\hline Pyraclostrobin & -0.0000 & 0.9364 & -0.00 & 1.000 & 1.00 & 0.16 & 6.27 \\
\hline Chlorothalonil & -1.7572 & 0.9537 & -1.84 & 0.170 & 0.17 & 0.03 & 1.12 \\
\hline
\end{tabular}

${ }^{\mathrm{z}} \log$ likelihood $=-87.247$. Test that all slopes are zero: $\mathrm{G}=435.81, \mathrm{DF}=18, P$ value $=0.000 . \mathrm{CI}=$ confidence interval. 
and selects for pathogen genotypes bearing certain mutations in the $\beta$-tubulin gene which can persist in the pathogen population due to disruptive selection long after the chemical has been withdrawn $(15,36)$. Such mutations have been related to specific amino acid substitutions at several regions of the $\beta$-tubulin gene. There have been reported cases of resistance to BENs in a number of different fungal species $(15,20,21,24,35,45,46,50)$. In this study, none of the C. gloeosporioides isolates (exposed and underexposed isolates) showed resistance to benomyl, and growth inhibition was comparable with sensitive $C$. gloeosporioides isolates reported elsewhere $(29,50)$. C. truncatum isolates from both pepper and papaya were only sensitive to benomyl at concentrations $\geq 100.0 \mu \mathrm{g} / \mathrm{ml}$. In $A B$ assays, increasing concentrations of benomyl resulted in reduced spore survival of $C$. gloeosporioides and $C$. truncatum isolates; however, the differential responses between $C$. gloeosporioides and C. truncatum isolates as recorded for AA assays was not apparent. This can be explained by the mode of action of these fungicides, where microtubule assembly impacts mitosis and cell division during hyphal extension and fungal growth (29); however, there is no effect on oxidative phosphorylation processes in spore mitochondria.

Sequence alignments between $C$. truncatum isolates from papaya and C. gloeosporioides f. sp. aeschynomene revealed two codon changes outside of the recognized codons usually associated with the BEN-resistant phenotype. The relationship between the BEN-resistant phenotype of these $C$. truncatum isolates and the identified codon changes in the $\beta$-tubulin gene sequence needs further verification because similar studies were not previously conducted for this Colletotrichum sp. It is unclear why no amplicons were obtained for $C$. truncatum isolates from pepper but one explanation may be that sufficient variation existed in the primer binding sites for these isolates, which reduced primer binding efficiency. Mutations in specific amino acids that confer BEN resistance occur at codon 198 or 200 in a number of fungal species $(36,38,71)$. Peres et al. (50) examined cognate $\beta$-tubulin gene sequences of $C$. acutatum isolates from citrus (generated by the TUB2-L/R primers) and determined that mutations that conferred resistance to BENs in these isolates were located outside of the 198 or 200 codons. Mutations reported to confer BEN resistance in fungal pathogens can have intra-specific or even intra-strain differ- ences with codon changes outside of the recognized 198 and 200 positions (e.g., at codon 165 in Aspergillus nidulans; 36), and may be more complex than previously thought, because stabilization dynamics and functioning of microtubule heterodimers in BENresistant isolates are also affected by temperature (58).

Copper-based fungicides have been used to control anthracnose in a number of fruit and vegetable crops; however, their use may be restricted in some cropping systems because of phytotoxic effects (2). The copper-based fungicide screened in this study had no effect on radial mycelial growth of Colletotrichum isolates regardless of species. However, the $\mathrm{AB}$ assay results indicated that increasing concentration inhibited spore survival for most isolates. This distinction was a result of the mode of action of copper-based chemistries. During germination, copper ions passively migrate into spores and accumulate to levels which become toxic (61). This emphasizes the importance of the $\mathrm{AB}$ assay in assessing sensitivity of fungal spores to different fungicides. Accuracy of fungicide sensitivity screening is improved when both $\mathrm{AA}$ and $\mathrm{AB}$ assays are conducted. The $\mathrm{AB}$ assay can identify chemicals that affect spore physiology as opposed to those that only affect hyphal extension (AA assay) (56).

Strobilurins or quinone outside inhibitor fungicides are an important class of fungicides with a site-specific mode of action. They interfere with mitochondrial respiration by binding to the outer quinine oxidizing pocket $\left(\mathrm{Q}_{\mathrm{o}}\right.$ complex) located on cytochrome $\mathrm{b}$ mitochondrial membrane protein. Transfer of electrons from cytochrome $b$ to cytochrome $c_{1}$ is disrupted and production of ATP is halted. Inhibition of ATP production directly prevents mycelial growth and spore germination, which are both energyand ATP-dependent processes $(9,11,25)$. The pyraclostrobin fungicide tested in this study caused significant reduction in mycelial growth regardless of species and host origin, according to AA and $\mathrm{AB}$ assays.

There have been numerous cases of resistance developing in the major classes of single-site inhibitors such as the BENs, pyrimidines, carboxanilides, phenylamides, sterol biosynthesis inhibitors, morpholines, and $\mathrm{Q}_{0}$ inhibitors for various fungal pathogens (11). Prevention of fungicide resistance is a priority and it is recommended that (i) mixes of single-site and multi-site fungicides

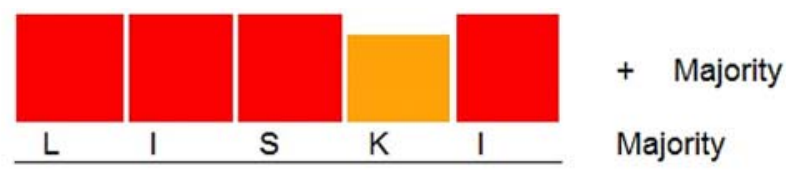

\begin{tabular}{|c|c|c|c|c|c|}
\hline \multirow[b]{2}{*}{1} & & & & & \\
\hline & L & I & $S$ & K & 1 \\
\hline 1 & L & I & $S$ & K & 1 \\
\hline 1 & L & 1 & $S$ & K & 1 \\
\hline 1 & L & 1 & 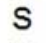 & K & 1 \\
\hline 1 & L & 1 & $S$ & K & I \\
\hline \multirow[t]{3}{*}{1} & L & 1 & $S$ & $\mathrm{R}$ & 1 \\
\hline & $\mathrm{T}$ & $F$ & $s$ & V & $\mathrm{V}$ \\
\hline & & & & & 20 \\
\hline 16 & $\mathrm{~T}$ & $F$ & $S$ & V & V \\
\hline 16 & $\mathrm{~T}$ & $F$ & $s$ & V & V \\
\hline 16 & $\mathrm{~T}$ & $F$ & $s$ & V & V \\
\hline 16 & $\mathrm{~T}$ & $F$ & $S$ & V & V \\
\hline 16 & $\mathrm{~T}$ & $F$ & $\mathrm{~s}$ & V & V \\
\hline 16 & $\mathrm{~T}$ & $F$ & $S$ & V & G \\
\hline
\end{tabular}

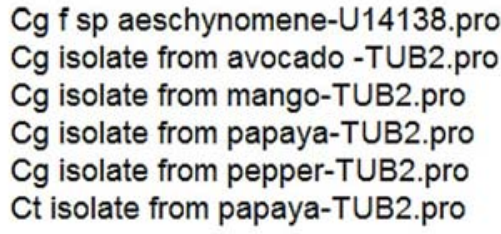

+ Majority

Majority

$\mathrm{Cg}$ f sp aeschynomene-U14138.pro
$\mathrm{Cg}$ isolate from avocado-TUB2.pro
$\mathrm{Cg}$ isolate from mango-TUB2.pro
$\mathrm{Cg}$ isolate from papaya-TUB2.pro
$\mathrm{Cg}$ isolate from pepper-TUB2.pro
$\mathrm{Ct}$ isolate from papaya-TUB2.pro

Fig. 2. Partial tubulin protein sequence alignment to illustrate amino acid changes at codons 154 and 170 in the Colletotrichum truncatum sequence (papaya isolates only) based on comparisons with the corresponding reference sequence of $C$. gloeosporioides $\mathrm{f}$. $\mathrm{sp}$. aeschynomene (GenBank accession number U14138). 
be used in rotation rather than at-risk fungicides alone, (ii) application of fungicides ideally should be on a needs basis instead of by calendar or prescription basis, (iii) only the recommended doses and application rates should be used, and (iv) integrated chemical and non-chemical strategies should be implemented for disease management $(13,58)$. Continuous monitoring of fungicide sensitivity based on in vitro bioassays that assess mycelial growth and spore germination, such as the ones utilized in this study, is essential to (i) detect shifts in EC values toward greater resistance, which would indicate directional selection; (ii) reduce the rate at which these shifts develop; and (iii) understand pathogen population dynamics under various chemical control regimes over time $(13,22)$. As with many in vitro bioassays, results may not always correlate with in vivo efficacy, and the predictive limitation of any bioassay must be considered in designing respective monitoring strategies.

\section{Acknowledgments}

This work was funded by The University of the West Indies, St. Augustine Campus Research and Publications Grant (grant number CRP.3.NOV11.8). We thank R. Rampersad and A. Hailey for their assistance.

\section{Literature Cited}

1. AbD SeroTec. AlamarBlue Technical Datasheet. www.ab-direct.com

2. Akem, C. N. 2006. Mango anthracnose disease: present status and future research priorities. Plant Pathol. J. 5:266-273.

3. Al-Nasiry, S., Geusens, N., Hanssens, M., Luyten, C., and Pijnenborg, R. 2007. The use of Alamar Blue assay for quantitative analysis of viability, migration and invasion of choriocarcinoma cells. Hum. Reprod. 22:13041309.

4. Alvarez, A. M., Hylin, J. W., and Ogata, J. N. 1977. Postharvest diseases of papaya reduced by biweekly orchard sprays. Plant Dis. Rep. 61:731-735.

5. Alvarez, A. M., and Nishijima, W. T. 1987. Postharvest diseases of papaya. Plant Dis. 71:681-686.

6. Anonymous. 1982. Recommended methods for the detection and measurement of resistance of agricultural pests to pesticides. FAO Plant Prot. Bull. 30:36-143.

7. Anonymous. 1991. FRAC methods for monitoring fungicide resistance. EPPO Bull. 21:291-354.

8. Arauz, L. F. 2000. Mango anthracnose: economic impact and current options for integrated management. Plant Dis. 84:600-611.

9. Avila-Adame, C., and Köller, W. 2002. Disruption of the alternative oxidase gene in Magnaporthe grisea and its impact on host infection. Mol. PlantMicrobe Interact. 15:493-500.

10. Bailey, J. A., and Jeger, M. J. 1992. Colletotrichum: Biology, Pathology and Control. CAB International, Wallingford, UK.

11. Bartlett, D. W., Clough, J. M., Godwin, J. R., Hall, A. A., Hamer, M., and Parr-Dobrzanski, B. 2002. The strobilurin fungicides. Pest. Manage. Sci. 58:649-662.

12. Belinsky, M., and Jaiswal, A. K. 1993. NAD(P)H: quinone oxidoreductase1DT-diaphorase) expression in normal and tumor tissues. Cancer Metastasis Rev. 12:103-117.

13. Beresford, R. 1994. Understanding fungicide resistance. Orchardist 67:24

14. Buhr, T. L., and Dickman, M. B. 1994. Isolation, characterization and expression of a second tubulin-encoding gene from Colletotrichum gloeosporioides f. sp. aeschynomene. Appl. Environ. Microbiol. 60:4155-4159.

15. Bus, V. G., Bongers, A. J., and Risse, L. A. 1991. Occurrence of Penicillium digitatum and $P$. italicum resistant to Benomyl, thiabendazole, and imazalil of citrus fruit from different geographic origins. Plant Dis. 75:1098-1100.

16. Chikuba, K., Yubisui, T., Shirabe, K., and Takeshita, M. 1994. Cloning and nucleotide sequence of a cDNA of the human erythrocyte NADPH-flavin reductase. Biochem. Biophys. Res. Commun. 198:1170-1176.

17. Collins, L., and Franzblau, S. G. 1997. Microplate Alamar blue assay versus BACTEC 460 system for high-throughput screening of compounds against Mycobacterium tuberculosis and Mycobacterium avium. Antimicrob. Agents Chemother. 41:1004-1009.

18. Cox, K. D., Quello, K., Deford, R. J., and Beckerman, J. L. 2009. A rapid method to quantify fungicide sensitivity in the brown rot pathogen Monilinia fructicola. Plant Dis. 93:328-331.

19. Damm, U., Woudenberg, J. H. C., Cannon, P. F., and Crous, P. W. 2009. Colletotrichum species with curved conidia from herbaceous hosts. Fungal Divers. 39:45-87.

20. Darvas, J., and Kotzé, J. M. 1987. Avocado fruit diseases and their control in South Africa. S. Afr. Avocado Grow. Assoc. Yearb. 10:117-119.

21. De Lapeyre De Bellaire, L., and Dubois, C. 1997. Distribution of thiabendazole resistant Colletotrichum musae isolates from Guadeloupe banana plantations. Plant Dis. 81:1378-1383.

22. Delp, C. J. 1980. Coping with resistance to plant disease. Plant Dis. 64:652657.

23. Everett, K. R., and Hallett, I. C. 1996. Infection of avocados by Colleto- trichum acutatum. Page 54 in: Proc. NZIAS/NZSHS Conv. Ruakura, Hamilton, New Zealand.

24. Farungsang, U., and Farungsang, N. 1992. Benomyl resistance of Colletotrichum spp. associated with rambutan and mango fruit rot in Thailand. Acta Hortic. 321:891-897.

25. Fernández-Ortuño, D., Torés, J. A., de Vicente, A., and Pérez-García, A. 2010. Mechanisms of resistance to QoI fungicides in phytopathogenic fungi. Int. Microbiol. 11:1-9.

26. Finney, D. J. 1971. Probit Analysis, 3rd ed. Cambridge University Press, Cambridge.

27. Food and Agriculture Organizations of the United Nations (FAO). 2011 http://faostat.fao.org/

28. Franzblau, S. G., Witzig, R. S., McLaughlin, J. C., Torres, P., Madico, G., Hernandez, A., Degnan, M. T., Cook, M. B., Quenzer, V. K., and Ferguson, R. M. 1998. Rapid, low-technology MIC determination with clinical Mycobacterium tuberculosis isolates by using the microplate Alamar Blue assay. J. Clin. Microbiol. 36:362-366.

29. Freeman, S., Katan, T., and Shabi, E., 1998. Characterization of Colletotrichum species responsible for anthracnose diseases of various fruits. Plan Dis. 82:596-605.

30. Fungicide Resistance Action Committee (FRAC). FRAC code list 2010 www.frac.info/

31. Glass, N. L., and Donaldson, G. C. 1995. Development of primer sets designed for use with the PCR to amplify conserved genes from filamentous ascomycetes. Appl. Environ. Microbiol. 61:1323-1330.

32. Goegan, P., Johnson G., and Vincent, R. 1995. Effects of serum protein and colloid on the Alamar blue assay in cell cultures. Toxic InVitro 9:257-266.

33. Holliday, P. 1980. Fungus Diseases of Tropical Crops. Cambridge University Press, Cambridge.

34. Jeffries, P., Dodd, J. C., Jeger, M. J., and Plumbley, R. A. 1990. The biology and control of Colletotrichum species on tropical fruit crops. Plant Pathol. 39:343-366.

35. Johnson, K. B., Sawyer, T. L., and Powelson, M. L. 1994. Frequency of benzimidazole and dicarboximide-resistant strains of Botrytis cinerea in western Oregon small fruit and snap bean plantings. Plant Dis. 78:572-577.

36. Jung, M. K., and Oakley, B. R. 1990. Identification of an amino acid substitution in benA, $\beta$-tubulin gene of Aspergillus nidulans that confers thiabendazole resistance and Benomyl supersensitivity. Cell Motil. Cytoskel. 17:87-94.

37. Khalil, I., Al-Mughrabi, and Gray, A. B. 1995. Competition between triadimefon-sensitive and triadimefon-resistant isolates of Erysiphe graminis f. sp. tritici. Plant Dis. 79:709-712.

38. Koenraadt, H., Somerville, S. C., and Jones, A. L. 1992. Characterization of mutations in the $\beta$-tubulin gene of Benomyl-resistant field strains of Venturia inaequalis and other plant pathogenic fungi. Mol. Plant Pathol. 82:13481354.

39. Larson, E. M., Doughman, D. J., Gregerson, D. S., and Obritsch, W. F. 1997. A new, simple, nonradioactive, nontoxic in vitro assay to monitor corneal endothelial cell viability. Invest. Ophthalmol. Vis. Sci. 38:1929-1933.

40. Lewis-Ivey, M. L., Nava Diaz, C., and Miller, S. A. 2004. Identification and management of Colletotrichum acutatum on immature bell peppers. Plant Dis. 88:1198-1204.

41. Mallick, E., Scutt, N., Scutt, A., and Rolf, C. 2009. Passage and concentration-dependent effects of indomethacin on tendon derived cells. J. Orthop. Surg. Res. 4:9.

42. Matsumoto, K., Yamada, Y., Takahashi, M., Todoroki, T., Mizoguchi, K. Misaki, H., and Yuki, H. 1990. Fluorometric determination of carnitine in serum with immobilized carnitine dehydrogenase and diaphorase. Clin. Chem. 36:2072-2076.

43. McBride, J., Ingram, P. R., Henriquez, F. L., and Roberts, C. W. 2005. Development of colorimetric microtiter plate assay for assessment of antimicrobials against acanthamoeba. J. Clin. Microbiol. 43:629-634.

44. Meletiadis, J., Mouton, J. W., Meis, J. F. G. M., Bouman, B. A., and Verweij, P. E. 2002. Comparison of the Etest and the sensititre colorimetric methods with the NCCLS proposed standard for antifungal susceptibility testing of Aspergillus species. J. Clin. Microbiol. 40:2876-2885.

45. Moorman, G. W., and Lease, R. J. 1992. Benzimidazole and dicarboximideresistant Botrytis cinerea from Pennsylvania greenhouses. Plant Dis. $76: 477-480$

46. Murray, T. D. 1996. Resistance to benzimidazole fungicides in the cerea eyespot pathogen, Pseudocercosporella herpotrichoides, in the Pacific Northwest 1984-1990. Plant Dis. 80:19-23.

47. Naqvi, S. A. M. H., ed. 2004. Diseases of Fruits and Vegetables-Diagnosis and Management, Volume II. Kluwer Academic Publishers, Dordrecht, The Netherlands.

48. Page, A. B., Page, A. M., and Noel, C. 1993. A new fluorimetric assay for cytotoxicity measurements in vitro. Int. J. Oncol. 3:473-476.

49. Pelloux-Prayer, A. L., Priem, B., and Joseleau, J. P. 1998. Kinetic evaluation of conidial germination of Botrytis cinerea by a spectrofluorometric method. Mycol. Res. 102:320-322.

50. Peres, N. A. R., Souza, N. L., Peever, T. L., and Timmer, L. W. 2004. Benomyl sensitivity of isolates of Colletotrichum acutatum and C. gloeosporioides from citrus. Plant Dis.88:125-130.

51. Pfaller, M. A., and Barry, A. L. 1994. Evaluation of a novel colorimetric 
broth microdilution method for antifungal susceptibility testing of yeast isolates. J. Clin. Microbiol. 32:1992-1996.

52. Pijls, C. F. N., Shaw, M. W., and Parker, A. 1994. A rapid test to evaluate in vitro sensitivity of Septoria tritici to flutriafol, using a microtiter plate reader. Plant Pathol. 43:726-732.

53. Ploetz, R. C. 2003. Diseases of Tropical Fruits. CABI Publishing, Wallingford, U.K.

54. Promega Corporation. Protocols and Applications Guide. Rev.8/06. www.promega.com

55. Quent, V. C., Loessner, D., Friis, T., Reichert, J. C., and Hutmacher, D. W. 2010. Discrepancies between metabolic activity and DNA content as tool to assess cell proliferation in cancer research. J. Cell. Mol. Med. 14:10031013.

56. Rampersad, S. N. 2011. A rapid colorimetric microtiter bioassay to evaluate fungicide sensitivity among Verticillium dahliae isolates. Plant Dis. 95:248255.

57. Rampersad, S. N. 2011. Molecular and phenotypic characterization of Colletotrichum species associated with anthracnose disease of papaya in Trinidad. Plant Dis. 95:1244-1254.

58. Russell, P. E. 1999. Fungicide resistance management: into the next millennium. Pestic. Outlook 213-215.

59. Sanders, G. M. 2000. Korsten, L., and Wehner, F. C. 2000. Survey of fungicide sensitivity in Colletotrichum gloeosporioides from different avocado and mango production areas in South Africa. Eur. J. Plant Pathol. 106:745-752.

60. Sepiah, M. 1994. Efficacy of propiconazole against fungi causing postharvest disease on Eksotika papaya. International Conference, Chaing Mai (Thailand). Australian Center for International Agricultural Research, Canberra, ACT, Australia.

61. Simmonds, J. H. 1966. A study of the species of Colletotrichum causing ripe fruit rots in Queensland. Queensl. J. Agric. Anim. Sci. 22:437-459.

62. Smith, K. L. 2000. Peppers. Pages 166-173 in: Ohio Vegetable Production Guide.
63. Tapia-Tussell, R., Quijano-Ramayo, A., Cortes-Velazquez, A., Lappe, P. Larque-Saavedra, A., and Perez-Brito, D. 2008. PCR-Based detection and characterization of the fungal pathogens Colletotrichum gloeosporioides and Colletotrichum capsici causing anthracnose in papaya (Carica papaya L.) in the Yucatan Peninsula. Mol. Biotechnol. 40:293-298.

64. Tarnowski, T. B. L., and Ploetz, R. C. 2010. First report of Colletotrichum capsici causing postharvest anthracnose on papaya in South Florida. Plant Dis. 94:1065.

65. Trek Diagnostic Systems. http://www.trekds.com/products/alamarBlue/

66. Vega, B., Liberti, D., Harmon, P. F., and Dewdney, M. M. 2012. A rapid resazurin-based microtiter assay to evaluate QoI sensitivity for Alternaria alternata isolates and their molecular characterization. Plant Dis. http://dx.doi.org/10.1094/PDIS-12-11-1037-RE

67. White, T. J., Bruns, T., Lee, S., and Taylor, J. 1990. Amplification and direct sequencing of fungal ribosomal RNA genes for phylogenetics. Pages 315-322 in: PCR Protocols: A Guide to Methods and Applications. M. A. Innis, D. H. Gelfand, J. J. Sninsky, and T. J. White, eds.. Academic Press, New York.

68. Whitelaw-Weckert, M. A., Curtin, S. J., Huang, R., Steel, C. C., Blanchard, C. L., and Roffey, P. E. 2007. Phylogenetic relationships and pathogenicity of Colletotrichum acutatum isolates from grape in subtropical Australia. Plant Pathol. 56:448-463.

69. Wood, P. M., and Holloman, D. W. 2003. Review: a critical evaluation of the role of alternative oxidase in the performance of strobilurin and related fungicides acting at the $\mathrm{Q}_{0}$ site of complex III. Pest Manage. Sci. 59:499511.

70. Yaguchi, Y., Nakanishi, Y., Saito, T., and Nakamura, S. 1995. Anthracnose of Carica papaya L. caused by Colletotrichum capsici. Ann. Phytopathol. Soc. Jpn. 61:222.

71. Yarden, O., and Katan, T. 1993. Mutations leading to substitutions at amino acids 198 and 200 of beta-tubulin that correlate with Benomyl-resistance phenotypes of field strains of Botrytis cinerea. Phytopathology 83:1478 1483. 